\title{
Support Technique of Horse Head in Weakly Cemented Soft Rock
}

\author{
Li Haixia*, Wang Zuhe, Xiu Yingchang and Wang Genxia
}

School of Shandong University of Science and Technology, Qingdao, Shandong, 266590, P.R. China

\begin{abstract}
Part of the chambers of the coalmine roadway in Western Inner Mongolia and Eastern Ningxia of China are in weakly consolidated soft rock formation. Taking the horse head engineering in Maiduoshan coal mine in the main level as an example, a new scheme was put forward to optimize the original supporting scheme. A three-dimensional numerical model of the project of horse head was set up. According to the rock composition, different layer has different material properties. Initial stress of the model was given according to the measure results of in-situ stress. Strain softening constitutive model was used in calculation. The mechanical softening of surrounding rock after excavation was studied by numerical analysis method. Numerical analysis was done before construction, and displacement of horse head surface was monitored in construction. The result of numerical analysis and the monitoring data are similar. Good effect has been achieved after the implementation of the project.
\end{abstract}

Keywords: Horse head, softening after peak, support technique, weakly cemented soft rock.

\section{INTRODUCTION}

The horse head is located in the throat of the mine, connecting shaft and shaft tunnel, shouldering the material equipment up and on waste rock discharge, staff lifting and other important functions. The gate is only supported reasonable and being kept stable for a long time, construction and production of coal mine could be in normal operation. Weakly cemented soft rock has stronger softening properties after peak, even having the appearance of brittle [1]. Studying on the process of rock after peak is very difficult because of the mechanical parameters of rock not only related with the stress state (such as confining pressure), but also related with the loading path (such as plastic strain increment), so there are often some constitutive models with quite complex softening properties leading to promotion problems [2, 3]. In practice, most of the supporting designers can not be accurate and convenient to consider the mechanical softening, how to calculate the range of wall rock looseness and the precision of supporting load are also problems [4]. So it is urgent to put forward the effective and simple support technique to determine the strain softening effect of weakly cemented soft rock. It has great difficulty of supporting the horse head in weakly cemented soft rock [5]. At the same time, and the cost of horse head engineering is much higher than the general tunnel because of its high importance and its long service life. It is necessary to study on the stability and supporting technology for the horse head, in order to realize the consistency on the safety, feasibility and economy of horse head engineering [6]. In addition, the water has a strong weathering softening effect on the weakly cemented soft rock, such as the rock strength of some soft rock with an exponential decrease with the change of moisture content
[7]. And the horse head, as well connected with the main shaft, will seriously suffer from borehole water, bottom water and so on. So it must analyze the harm of the water to the horse head and put forward to effective measures of prevention and controlling of water hazards [8].

In this paper, it took the horse head engineering in the main level of auxiliary shaft in Maiduoshan coal mine in Ningxia as the research background [9]. According to the properties of weakly cemented soft rock and the influence factors of the horse head stability and its mechanism, it established reasonable and effective supporting technology of horse head in weakly cemented soft rock and compared the tests data with the old one. Then it studied the stability of horse head in weakly cemented soft rock strata and its supporting technology and provided the reference for the similar engineering construction of horse head in coal mines.

\section{THE ORIGINAL SUPPORT SCHEME OF THE HORSE HEAD}

Net diameter of the shaft was $9.4 \mathrm{~m}$; the wall thickness was $600 \mathrm{~mm}$ with $\mathrm{C} 60$ concrete reinforced. Then pour concrete after assembled steel formwork. The wellbore rock was supported without bolt and mesh; the horse head chamber was the straight wall with the shape of arch, size as shown in Fig. (1). port.

The first support was the common bolt-shot Crete sup-

(1) The bolt was full thread resin bolt of $\Phi 20 \mathrm{~mm}$ and of Length $2200 \mathrm{~mm}$, Row \& Line Space $700 \times 700 \mathrm{~mm}$. Each anchor was anchored by 2 pieces of anchor resistant coil.

(2) The specification of steel mesh patch was $\Phi 6.5 \mathrm{~mm}$ round steel and $100 \times 100 \mathrm{~mm}$ mesh.

(3) The thickness of shot Crete was $100 \mathrm{~mm}$. The strength is C20. 
The secondary support was lining of reinforced concrete with $600 \mathrm{~mm}$ thickness and C60 strength.

The specification of main reinforcement was $\Phi 25 \times @ 300 \times 300$ mm.

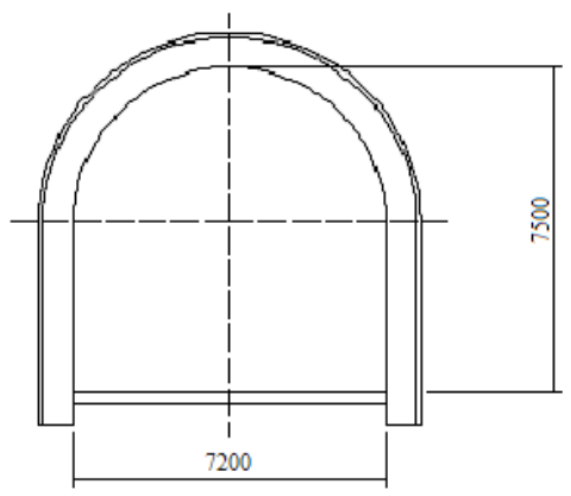

Fig. (1). Chamber section of the original design.

\section{THE NEW SUPPORT SCHEME OF HORSE HEAD}

\subsection{The Parameters of Supporting of a Shaft Lining}

(1) Support of the upper portion of the wellbore

Support of wellbore of Height $9 \mathrm{~m}$ :

(1)Hanging net and grunting technology measures were carried out accordance with the original design. The metal net was processed with $\varphi 6.5 \mathrm{~mm}$ steel bar. The Specification of the mesh was $100 \times 100 \mathrm{~mm}$. The labeling of shot Crete was $\mathrm{C} 25$.

(2)The bolt was screw-thread steel bolt of $\varphi 20 \mathrm{~mm} \times 2800 \mathrm{~mm}$, row \& line space $1400 \times 1400 \mathrm{~mm}$. Each anchor was anchored by 2 pieces of anchor resistant coil. Arrange the bolt perpendicular to the contour lined of the shaft or tunnel. The support plate was made of $150 \times 150 \times 10 \mathrm{~mm}$ Q235 steel. The model of resin explosive roll was MSK2370. Each anchor was anchored by 2 pieces of resin explosive roll.

(3) Anchor cable was of $\varphi 17.8 \times 7200 \mathrm{~mm}$ steel with setting 4 pieces of resin explosive roll anchorage cable. The tensile resistance force of anchor was more than $30 t$, row \& line space $1400 \times 1400 \mathrm{~mm}$. The backing plate was $\varphi 300 \times 20 \mathrm{~mm}$. This section of the wellbore inclination was arranged in the upper part of anchor cable.

(2) Support of wellbore inclination intersecting line

A collection of anchor: 3 pieces of $\varphi 17.8$ steel strand with length $21 \mathrm{~m}$. The depth of the hole was $20 \mathrm{~m}$, The angle between the hole and the horizontal direction was $5^{\circ} \sim 15^{\circ}$ and row \& line space $2100 \times 2100 \mathrm{~mm}$. The backing plate was $\varphi 300 \times 20 \mathrm{~mm}$.

The bolt: screw-thread steel bolt of $\varphi 20 \mathrm{~mm} \times 2800 \mathrm{~mm}$, row \& line space $700 \times 700 \mathrm{~mm}$. Arrange the bolt perpendicular to the contour lines of the shaft or tunnel. The support plate was made of $150 \times 150 \times 10 \mathrm{~mm}$ Q235 steel.

(3) Support of the lower portion of the wellbore

Anchor cable was of $\varphi 17.8 \times 7200 \mathrm{~mm}$, horizontal direction, row \& line space $1400 \times 1400 \mathrm{~mm}$. The backing plate was $\varphi 300 \times 20 \mathrm{~mm}$, row \& line space between anchors $1400 \times 1400 \mathrm{~mm}$.

\subsection{The Support Parameter of Horse Head Chamber}

The main chamber section of horse head was shown in Fig. (2).

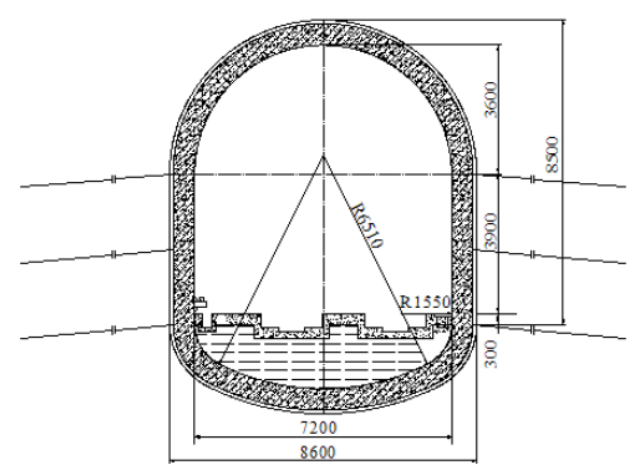

Fig. (2). The main chamber section of horse head.

The support parameter of a new scheme in horse head chamber was as follows:

(1) OOM15-1 anchor cable, anchoring by 4 pieces of resin explosive rolls. The depth of the hole was $7 \mathrm{~m}$. The aperture was $32 \mathrm{~mm}$. The length of the cable was $7.2 \mathrm{~m}$. The support plate was made of $\varphi 300 \times 20 \mathrm{~mm}$, row \& line space $1400 \times 1400 \mathrm{~mm}$, a single tension to design carrying capacity.

(2) 3 OOM15-3 anchor cable, anchoring by cement mortar. The depth of the hole was $20 \mathrm{~m}$. The aperture was $90 \mathrm{~mm}$. The length of the collection of anchor cable was $21 \mathrm{~m}$. The support plate was made of $\varphi 300 \times 20 \mathrm{~mm}$. The strength of mortar pouring was formed in 28 days. The tensioning forces of each steel strand requires 10 tons.

(3) Construct the conventional single strand cable after the first spraying and the collection of anchor cable before the second spraying.

\section{THE NUMERICAL ANALYSIS BETWEEN THE NEW SCHEME IN HORSE HEAD AND THE ORIGI- NAL ONE}

The scanning pictures of anchor cable supporting system in supporting schemes are shown in Fig. (3) and Fig. (4).

It includes three types of heating transformation methods: Conduction, Convection and Radiation, which seem to be complex for the analyses of heating transformation.

\subsection{The Range of Softening in Coffer Mechanics}

The new scheme was better controlling the rock deformation.

(1) In the new scheme the deformation in the bottom of chamber was more uniform and no partial deformation.

(2) The biggest vertical displacement at the bottom in the original scheme was $17.6 \mathrm{~cm}$. The biggest vertical displacement at the bottom in the new scheme was $9.72 \mathrm{~cm}$. The deformation of surrounding rock at the bottom has been effectively controlled. 


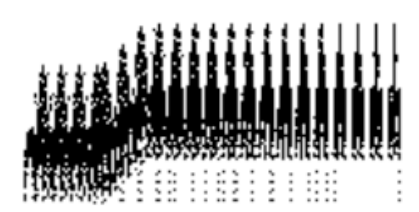

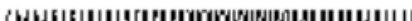

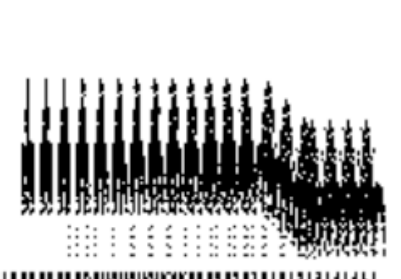

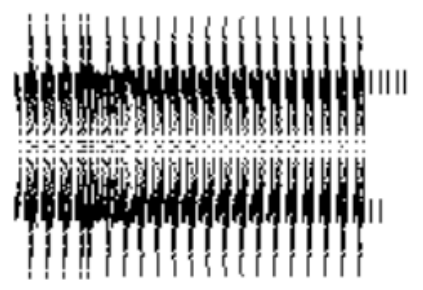

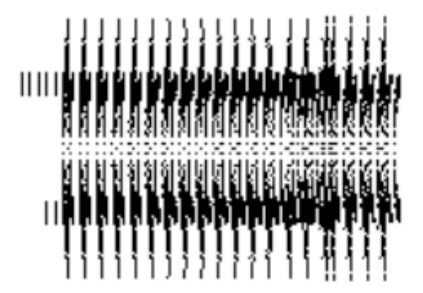

a. front view

b. top view

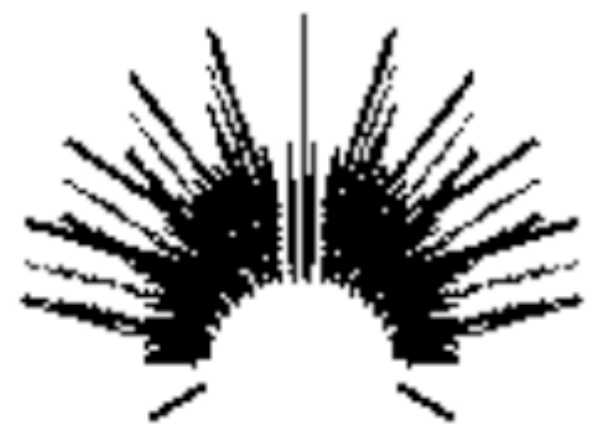

c. side view

Fig. (3). The original anchor cable support system.

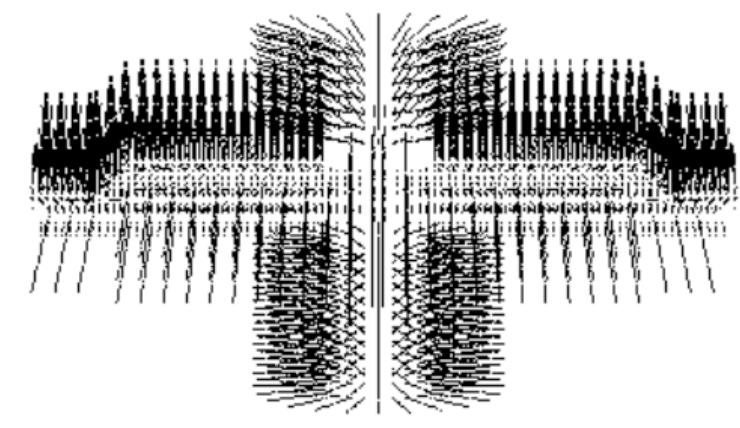

a. front view

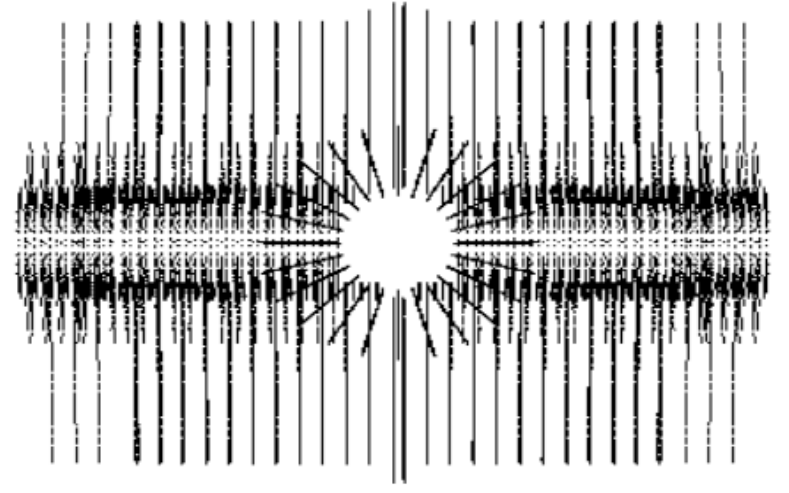

b. top view

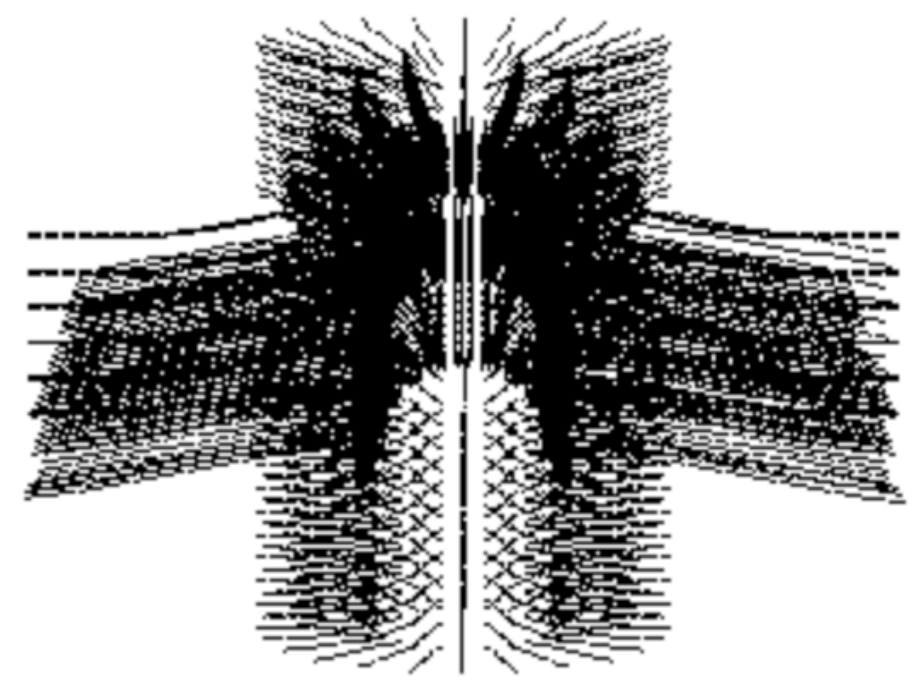

c. side view

Fig. (4). The new anchor cable support system. 


\subsection{The Displacement Growth of Surrounding Rock}

The new scheme was better controlling the rock deformation.

(1) In the new scheme the deformation in the bottom of chamber was more uniform and no partial deformation.

(2) The biggest vertical displacement at the bottom in the original scheme was $17.6 \mathrm{~cm}$. The biggest vertical displacement at the bottom in the new scheme was $9.72 \mathrm{~cm}$. The deformation of surrounding rock at the bottom has been effectively controlled.

\subsection{Changes of Surrounding Rock Stress}

Analysis was chart of stress of softening zone based on the new scheme according to the original scheme of surrounding rock after supporting can give out the following conclusions:

(1) There was tensile stress in the original scheme (In FLAC3D the stress was positive), and in the new scheme there was no this kind of stress existing.

(2) The stress becomes uniform on both sides of the bottom of the horse head chamber in the new scheme.

\section{COMPARING DISPLACEMENT CALCULATED WITH THAT MONITORED}

The calculated value and the monitoring value have similar change trend. Concrete conditions are as follows:

(1) In Fig. (5) a, the top displacement value reaches to the maximum in the intersecting line position and decreases to the two sides, which reflects the effects of intersecting line to the top chamber rock near the wellbore.

(2) In Fig. (5) b, in the bottom of the right of horse head the uplifted displacement value was larger.

(3) In Fig. (5) c, the displacement value reaches to the maximum in the intersecting line position and decreases to the two sides.

(4) The displacement trend was the same as the stability of the horse head. At the bottom of the right side and the intersecting line in the middle and the two sides of the horse head there was poor stability but larger displacement value.

Compare with the calculation of each monitoring section and the monitoring displacement in three cases at the top, bottom, two sides, get Fig. (5). The horizontal coordinate diagram was the monitoring section position ( 0 points for the shaft center, other coordinates for each monitoring section); longitudinal coordinate for all types of displacement.

From Fig. (5) we know that the displacement calculation value and the monitoring value were of similar size, and they were in the allowable range, which shows the good effect of the new scheme supporting.

Based on the above analysis was, we can give out some remedial measures for the Horse head of Maiduoshan coal mine in the main level, as follows:

(1) When in the same section of bolt (cable) the dynamometer number was above average, the surrounding rock pressure here was larger. According to the coupling support theory, it should be timely increased the bolt (cable) density, to achieve the same section of bolt (cable) interaction and no weak link.

(2) According to the principle of New Austrian Method, it should be timely supported again when the bolt (cable) reached to the certain value force.

(3) When a depth of surrounding rock displacement increases faster or convergence deformation value exceeds a certain value, we can know that the surrounding rock was severely damaged, it should be timely grouting stabilization.

(4) When the numerical roof displacement monitor increases more faster or the total displacement was more than a certain value, it should timely make evacuation of staff with adopting a bolt (cable) and more U steels and grouting methods to prevent the roof fall accidents and ensure the safety of construction chamber.

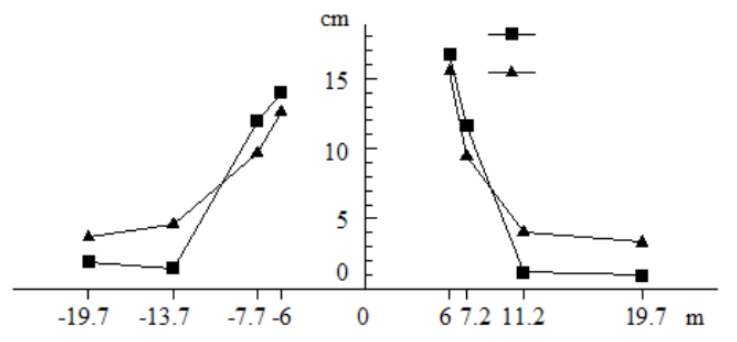

a. Settlement on top
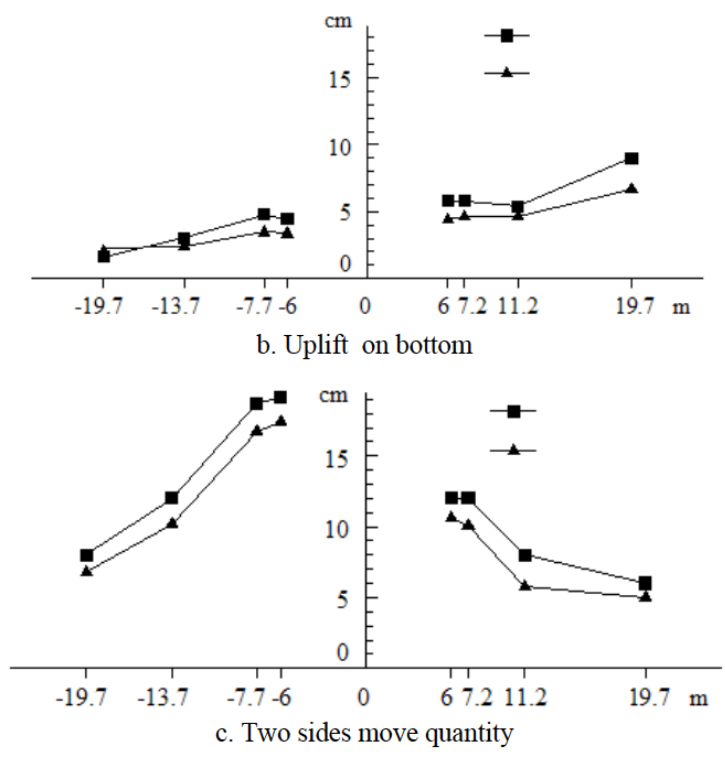

Fig. (5). Comparing displacement calculated with that monitored.

\section{CONCLUSION}

It researches on the horse head supporting technology of weakly cemented soft rock strata. As the stability of horse head is not good enough, it can be chosen the following available supporting technology:

(1) Focus on supporting destruction of the site excavation;

(2) Choose the reasonable value of bond strength between anchoring agent and the hole walls of weakly cemented soft rock; 
(3) Take comprehensive water prevention.

The new supporting technology of Maiduoshan coal mine in the main level:

(1) Reinforce the horse head and the two sides of chambers with cluster and anchor;

(2) The whole bolting and reinforce the top with common anchor;

(3) Technology of water prevention such as into the water + inhibiting the rock mechanics + rock softening grouting + closed concrete lining water prevention.

(4) Replacement at the bottom and local rounding.

Optimize the original program and then propose a new program. Through the numerical analysis, comparison of the two schemes, the calculation results show that at three aspects such as the softening, the surrounding rock displacement and the new scheme, the new program has much better result. The implementation of the new scheme monitors the surface displacement of horse head. On one hand compared with the results of numerical analysis it is consistent, on the other hand, the displacement values are within the allowable range, so the effect of supporting engineering of the new scheme is good. Research on rick hill mine horse head support technology for similar formations in the project has a larger reference value.

\section{CONFLICT OF INTEREST}

The authors confirm that this article content has no conflict of interest.

\section{ACKNOWLEDGEMENTS}

This work was financially supported by the National Natural Science Foundation of China (51304235; 51104094) and the Graduate Student Science and Technology Innovation Foundation of Shandong University of Science and Technology (YC150366).

\section{REFERENCES}

[1] S. L. Wang, Z. J. WU and C. G. Li, "Modeling of strain-softening and analysis of a lining for circular tunnel", Rock and Soil Mechanics, vol. 31, no. 6, pp. 1929-1936, 2010.

[2] L. F. Li, A. B. Jin, F. G. Deng and B. Liu, "Numerical simulation analysis of wall rock stability at intersection of tunneling in soft rock", China Mining Magazine, vol. 20, no. 9, pp. 84-86,91, 2011.

[3] X. H. Li, "Research on backwall grouting technology of horse head in Jiangjun coal mine auxiliary shaft," Mining Technology, vol. 12, no. 4, pp. 51-52, 2012.

[4] H. F. Lin, "Study of soft rock roadway support technique", Procedia Engineering, vol. 26, no. 4, pp. 321-326, 2011.

[5] B. Y. Zhang, J.H. Zhang and G.L. Sun, "Development of a softrock weathering test apparatus", Experimental Techniques, vol. 12, no. 2 , pp. 54-65, 2014

[6] J. H. Liu, H. G. Ji, Z. P. He and X. M. Zhou, "Study on performance and microstructure of new type sealing material suitable for freezing hole at weakly cemented soft rock", Journal of the China Coal Society, vol. 30, no. 4, pp. 595-599, 2013.

[7] C. H. Zhang, Q. S. Zhao and Y. J. Yu, "Dilation model of heterogeneous rock affected by confined pressure", Journal of Mining and Safety Engineering, vol. 28, no. 3, pp. 436-440, 2011.

[8] C. J. Deng, Y. R. Zheng, K. Wang and F. Gao, "Some discussion on the dilatancy of geotechnical materials", Chinese Journal of Geotechnical Engineering, vol. 31, no. 7, pp. 1110-1114, 2009.

[9] P. Hu, M. S. Huang, S. K. Ma and X. L. Lv, "True triaxial tests and strength characteristics of silty sand", Rock and Soil Mechanics, vol. 32, no. 2, pp. 465-470, 2011.

\footnotetext{
Received: May 26, 2015

(C) Haixia et al.; Licensee Bentham Open.
}

Revised: July 14, 2015

Accepted: August 10, 2015

This is an open access article licensed under the terms of the (https://creativecommons.org/licenses/by/4.0/legalcode), which permits unrestricted, noncommercial use, distribution and reproduction in any medium, provided the work is properly cited. 